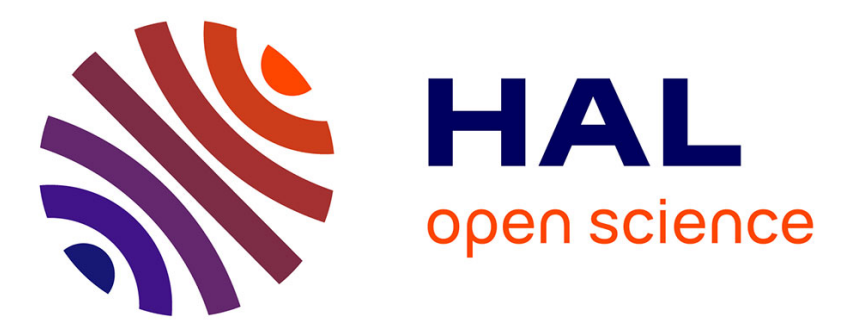

\title{
Mono- And hexa-palladium doped silver nanoclusters stabilized by dithiolates
}

Subrat Kumar Barik, Tzu-Hao Chiu, Yu-Chiao Liu, Ming-Hsi Chiang, Franck Gam, Isaac Chantrenne, Samia Kahlal, Jean-Yves Saillard, C.W. Liu

\section{- To cite this version:}

Subrat Kumar Barik, Tzu-Hao Chiu, Yu-Chiao Liu, Ming-Hsi Chiang, Franck Gam, et al.. MonoAnd hexa-palladium doped silver nanoclusters stabilized by dithiolates. Nanoscale, 2019, 11 (31), pp.14581-14586. 10.1039/c9nr05068j . hal-02281736

\section{HAL Id: hal-02281736 \\ https://hal-univ-rennes1.archives-ouvertes.fr/hal-02281736}

Submitted on 2 Dec 2019

HAL is a multi-disciplinary open access archive for the deposit and dissemination of scientific research documents, whether they are published or not. The documents may come from teaching and research institutions in France or abroad, or from public or private research centers.
L'archive ouverte pluridisciplinaire HAL, est destinée au dépôt et à la diffusion de documents scientifiques de niveau recherche, publiés ou non, émanant des établissements d'enseignement et de recherche français ou étrangers, des laboratoires publics ou privés. 


\title{
Mono- and hexa-palladium doped silver nanoclusters stabilized by dithiolates
}

\author{
Subrat Kumar Barik, ${ }^{\mathrm{a}}$ Tzu-Hao Chiu, ${ }^{\mathrm{a}}$ Yu-Chiao Liu, ${ }^{\mathrm{b}}$ Ming-Hsi Chiang, ${ }^{* \mathrm{~b}}$ Franck Gam, ${ }^{\mathrm{c}}$ Isaac \\ Chantrenne, ${ }^{c}$ Samia Kahlal, ${ }^{c}$ Jean-Yves Saillard, ${ }^{* c}$ and C. W. Liu*a
}

The synthesis via a co-reduction method of the first Pd-containing silver-rich 21-metal-atom nanocluster passivated by dithiolates, $\left[\mathrm{PdAg}_{20}\left\{\mathrm{~S}_{2} \mathrm{P}\left(\mathrm{O}^{n} \mathrm{Pr}\right)_{2}\right\}_{12}\right](1)$, is reported. 1 is an 8 electron superatom isoelectronic to $\left[\mathrm{Ag}_{21}\left\{\mathrm{~S}_{2} \mathrm{P}\left(\mathrm{O}^{i} \mathrm{Pr}\right)_{2}\right\}_{12}\right]^{+}$. Doping of $\mathrm{Pd}$ in 1 leads to its high stability against degradation in solution and shows a red emission in MeTHF at $77 \mathrm{~K}$. In addition, we report a multi palladium doped silver nanocluster, $\left[\mathrm{Pd}_{6} \mathrm{Ag}_{14}(\mathrm{~S})\left\{\mathrm{S}_{2} \mathrm{P}\left(\mathrm{O}^{n} \mathrm{Pr}\right)_{2}\right\}_{12}\right]$ (2) for the first time. Its $\mathrm{X}$-ray structure exhibits a sulfide-centered $\mathrm{Pd}_{6} \mathbf{A g}_{2}$ rhombohedron surrounded by tweleve additional silver atoms with $S_{6}$ symmetry. XPS study and DFT calculations indicate that 2 contains $\mathrm{Pd}(0)$ and $\mathrm{Ag}(\mathrm{I})$ metals. $\mathrm{A}$ significant decrease in the electrochemical gap was observed in the SWVs of 2.

\section{Introduction}

Over the past few years, atomically and structurally precise bimetallic alloy nanoclusters (NCs) have engrossed substantial research interest owing to their synergetic and enhanced optical, ${ }^{1}$ catalytic, $^{2}$ and electrochemical ${ }^{3}$ properties compared with their homometallic counterparts of which related new advances should be also noted. ${ }^{4}$ In this context, several structurally precise alloy $\mathrm{NCs}$ were produced from $\mathrm{Au}_{25}(\mathrm{SR})_{18}$ via doping of $\mathrm{Pd},{ }^{2 e,}, 5 \mathrm{Pt},{ }^{2 a}, 6 \mathrm{Cd},{ }^{7} \mathrm{Hg},{ }^{8} \mathrm{Cu},{ }^{9}$ and $\mathrm{Ag} .{ }^{10}$ In particular, the studies unraveled that the doping of $\left[\mathrm{Au}_{25}(\mathrm{SR})_{18}\right]^{-}$with a single Pd or Pt atom not only increases cluster stability but also drastically enhances catalytic efficiency. ${ }^{2 a, e}$

In case of silver, owing to its instability limitation (oxidation), only a handful of doped Ag NCs such as $\mathrm{MAg}_{24}$ (M $=\mathrm{Pd}$ or $\mathrm{Pt}),{ }^{11} \mathrm{Pt}_{2} \mathrm{Ag}_{23},{ }^{12} \mathrm{PtAg}_{28,}{ }^{13} \mathrm{PtAg}_{42,}{ }^{14}$ and $\mathrm{PtAg}_{26},{ }^{15}$ have

\footnotetext{
Department of Chemistry, National Dong Hwa University

No. 1 Sec. 2, Da Hsueh Rd., Shoufeng, Hualien 97401, Taiwan (R.O.C.)

E-mail: chenwei@mail.ndhu.edu.tw

Homepage: http://faculty.ndhu.edu.tw/ cwl/index.htm

b. Institute of Chemistry, Academia Sinica

Taipei, 11528, Taiwan (R.O.C.)

Univ Rennes, CNRS, ISCR-UMR 6226, F-35000 Rennes, France

E-mail: jean-yves.saillard@univ-rennes1.fr

+ Electronic Supplementary Information (ESI) available: Experimental data variable temperature NMR spectra $\left({ }^{31} \mathrm{P}\right)$, cyclic voltammetry, XPS and theoretical data of 1 and 2. See DOI: 10.1039/x0xx00000x
}

been structurally characterized. In addition, AuAg and other alloy $\mathrm{NCs}^{16}$ also have been documented to achieve improved catalytic and optical properties. For example, $\mathrm{Wu}$ and coworkers showed significant tuning in the structural and photoluminescence properties via doping of $\mathrm{Pd} / \mathrm{Pt} / \mathrm{Au}$ atoms into $\mathrm{Ag}_{25}(\mathrm{SR})_{18} \quad\left(\mathrm{SR}=\right.$ 2,4-dimethylbenzenethiolate) $\mathrm{NC} \cdot{ }^{17}$ Recently, Zhu et al. ${ }^{\mathrm{b} b}$ revealed that the central doping of $\mathrm{Pd}, \mathrm{Pt}$ or $\mathrm{Au}$ into an $\mathrm{Ag}_{25}$ cluster has a significant influence on the catalytic performance in the carboxylation reaction of $\mathrm{CO}_{2}$ with terminal alkyne through $\mathrm{C}-\mathrm{C}$ bond formation. Given the prominence of $\mathrm{Pd}$ doped noble metal NCs, it is indeed extremely essential to generate different sizes of Pd-doped $\mathrm{Ag}$ clusters and thus to study their structure/property correlation. Surprisingly, only one anionic mono palladium doped Ag NC with different thiolates has been structurally characterized till date: $\left[\mathrm{PdAg}_{24}(\mathrm{SR})_{18}\right]^{2-}{ }^{1 a, 11}$ This is largely due to the challenge of discriminating $\mathrm{Pd}$ from $\mathrm{Ag}$ since their atomic masses differ by merely $1.45 \mathrm{Da}$. Note that, an attempt to isolate $\mathrm{Pd}$ doped $\mathrm{Ag}$ $\mathrm{NC}$ by Chen et al. culminated in the synthesis of $\mathrm{Ag}_{33} \mathrm{NC}$ rather than the doped one of late. ${ }^{18}$ As a part of research on heavy atom doping on $\mathrm{Ag}$ and $\mathrm{Cu} \mathrm{NCs}$, we have recently produced structurally precise alloy $\mathrm{NCs}\left[\mathrm{AuAg}_{19}\left\{\mathrm{~S}_{2} \mathrm{P}\left(\mathrm{O}^{n} \mathrm{Pr}\right)_{2}\right\}_{12}\right],{ }^{19}$ $\left[\mathrm{AuAg}_{20}\left\{\mathrm{Se}_{2} \mathrm{P}(\mathrm{OEt})_{2}\right\}_{12}\right]^{+20}$ and $\left[\mathrm{PdCu}_{14} \mathrm{H}_{2}\left\{\mathrm{~S}_{2} \mathrm{CN}^{n} \mathrm{Bu}_{2} / \mathrm{S}_{2} \mathrm{P}\left(\mathrm{O}^{\prime} \mathrm{Pr}\right)_{2}\right\}_{6}(\mathrm{C} \equiv \mathrm{CPh})_{6}\right] . .^{21}$ in this study we isolated two unprecedented 21 and 20 metal based $\mathrm{Pd}$ doped Ag NCs $\left[\mathrm{PdAg}{ }_{20}\left\{\mathrm{~S}_{2} \mathrm{P}\left(\mathrm{O}^{n} \mathrm{Pr}\right)_{2}\right\}_{12}\right](\mathbf{1})$ and $\left[\mathrm{Pd}_{6} \mathrm{Ag}_{14}(\mathrm{~S})\left\{\mathrm{S}_{2} \mathrm{P}\left(\mathrm{O}^{n} \mathrm{Pr}\right)_{2}\right\}_{12}\right]$ (2), respectively. The results provide that the cluster $\mathbf{2}$ is the first evidence of multi palladium doped Ag NC characterized by single-crystal X-ray diffraction study.

\section{Results and discussion}

In a typical one pot synthetic method, co-reduction of metal precursors $\left[\mathrm{Ag}\left(\mathrm{CH}_{3} \mathrm{CN}\right)_{4}\right]\left(\mathrm{PF}_{6}\right)$ and $\left[\mathrm{Pd}\left\{\mathrm{S}_{2} \mathrm{P}\left(\mathrm{O}^{n} \mathrm{Pr}\right)_{2}\right\}_{2}\right]$ in the presence of $\mathrm{NH}_{4}\left[\mathrm{~S}_{2} \mathrm{P}\left(\mathrm{O}^{n} \mathrm{Pr}\right)_{2}\right]$ using $\mathrm{LiBH}_{4} \cdot \mathrm{THF}$ as a reducing agent resulted in the isolation of $\left[\mathrm{PdAg}_{20}\left\{\mathrm{~S}_{2} \mathrm{P}\left(\mathrm{O}^{n} \mathrm{Pr}\right)_{2}\right\}_{12}\right](\mathbf{1})$ as brown red solids in $34 \%$ yield (Scheme S1, ESIt). 1 was characterized by UV-vis, ${ }^{31} \mathrm{P}$ and ${ }^{1} \mathrm{H}$ NMR spectroscopy, ESI mass spectrometry, and and X-ray photoelectron spectroscopy (XPS). Its ${ }^{31} \mathrm{P}$ NMR spectrum shows a signal at $104.9 \mathrm{ppm}$ at 
(a)

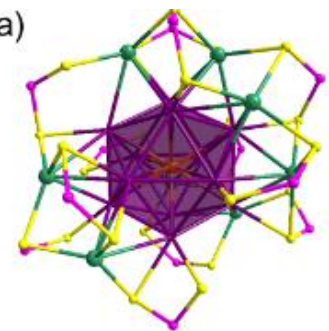

(c)

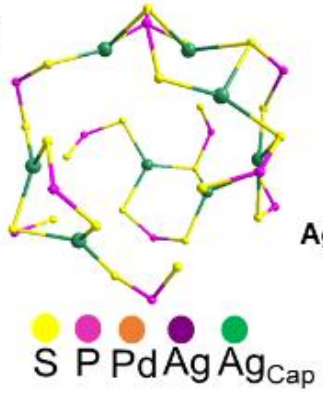

(b)

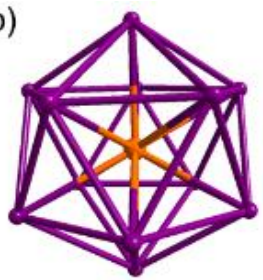

(d)

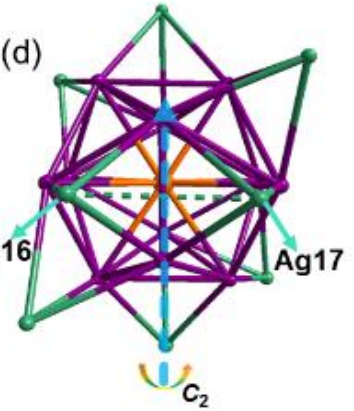

Fig. 1 (a) Total structure of $\left[\mathrm{PdAg}_{20}\left\{\mathrm{~S}_{2} \mathrm{P}\left(\mathrm{O}^{n} \mathrm{Pr}\right)_{2}\right\}_{12}\right]$ (1) (propoxy groups omitted for clarity) (b) $\mathrm{Pd@Ag} 12$ icosahedron core without capping $\mathrm{Ag}$ atoms; dtp ligands omitted for clarity. (c) The capping silver atoms connected with 12 dtp ligands surrounding Pd@Ag 12 icosahedron. (d) The pseudo- $C_{2}$ axis in the $\mathrm{PdAg}_{20}$ framework.

room temperature (Fig. S1, ESI ${ }^{+}$) and ${ }^{1} \mathrm{H}$ NMR spectrum shows signals corresponding to ${ }^{n} \mathrm{Pr}$ group (Fig. S2, ESI†). Thus both ${ }^{31} \mathrm{P}$ and ${ }^{1} \mathrm{H}$ NMR spectra confirm the presence of di-propyl dithiophosphate (dtp) ligands in the cluster. The positive-ion ESI mass spectrum of $\mathbf{1}$ displays a prominent band corresponding to [1+Ag] ${ }^{+}$at $\mathrm{m} / \mathrm{z} 4930.8$ (calcd. 4930.9), and its simulated isotopic pattern matches well with the experimental observation (Fig. S3, ESI + ). 1 crystallizes in the monoclinic $P 2_{1} / c$ space group. Its solid state structure unveiled a centered icosahedral Pd@Ag 12 core stabilized by 8 capping Ag atoms and $12 \mathrm{dtp}$ ligands (Fig. 1). This makes 1 a new member of the 8-electron $\left[\mathrm{MAg}_{20}\left\{\mathrm{E}_{2} \mathrm{P}(\mathrm{OR})_{2}\right\}_{12}\right]^{+}\left(\mathrm{M}=\mathrm{Ag}, \mathrm{Au} ; \mathrm{E}=\mathrm{S}\right.$, Se; $\mathrm{R}={ }^{i} \mathrm{Pr}$, Et) family. ${ }^{20,22,23}$ However, 1 differs from its congeners with respect to the configuration of the 8 capping silvers, which confers to the $M_{21}$ core an unprecedented idealized $C_{2}$ symmetry (Fig. 1a-C and Fig. S4, ESI + ), whereas only $T_{h}$ and $D_{3}$ core symmetries are known so far. ${ }^{20,22}$ It has been shown that these different decorations around the icosahedral core are close in energy. ${ }^{24}$ Their origination is likely the result of subtle (steric or kinetic) factors. Considering the ligands, the whole molecular symmetry of $\mathbf{1}$ is $C_{1}$.

The twelve dtp ligands are equally distributed in three layers (top, middle and bottom) around the pseudo- $C_{2}$ axis (Fig. 1c and Fig. S4, ESIt). They are coordinated to both capping and icosahedral silver atoms $\left(\mathrm{Ag}_{\text {cap }}\right.$ and $\mathrm{Ag}_{\text {ico, }}$, respectively) in four binding modes in a ratio of 2:4:4:2; bimetallic triconnectivity $\left(\eta^{2}: \mu_{2}, \mu_{1}\right)$, trimetallic triconnectivity $\left(\eta^{3}: \mu_{2}, \mu_{1}\right)$, trimetallic tetraconnectivity $\left(\eta^{3}: \mu_{2}, \mu_{2}\right)$ and tetrametallic tetraconnectivity $\left(\eta^{4}: \mu_{2}, \mu_{2}\right)$ (Fig. S5, ESIt). The

average $A g_{i c o-} \mathrm{S}(2.687 \AA)$ and $A g_{\text {cap }}-\mathrm{S}(2.540 \AA)$ distances are analogous to those observed in $\left[\mathrm{Ag}_{21}\left\{\mathrm{~S}_{2} \mathrm{P}\left(\mathrm{O}^{\prime} \mathrm{Pr}\right)_{2}\right\}_{12}\right]^{+}$(hereon $\left.\mathrm{Ag}_{21}\right)\left(2.670 \AA\right.$ and $\mathrm{Ag}_{\text {cap }}=2.510 \AA$, respectively $) .{ }^{22}$ The existence of four types of dtp coordination environment in the $\mathrm{X}$-ray structure encouraged us to investigate the variable temperature (VT) ${ }^{31} \mathrm{P}$ NMR spectrum of $\mathbf{1}$. As the temperature was lowered from room temperature (RT) to $-40{ }^{\circ} \mathrm{C}$, the signal at $103.9 \mathrm{ppm}$ split into four resonances at 106.5, 104.9, 104.5 and $103.7 \mathrm{ppm}$ (Fig. S6, ESIT). Further lowering of temperature resulted in peak sharpening. This solution behaviour is consistent with the $\mathrm{X}$-ray results.

The high-resolution $\mathrm{X}$-ray photoelectron spectroscopy (XPS) spectrum of 1 in the $P d 3 d$ region reveals binding energies at 335.9 and $341.1 \mathrm{eV}$, corresponding to $\mathrm{Pd}(0) 3 \mathrm{~d}_{5 / 2}$ and $3 d_{3 / 2}$ respectively (Fig. S7, ESI + ). In comparison to its homometallic analogue $\mathrm{Ag}_{21}{ }^{22}$ As expected, the incoporation of $\mathrm{Pd}$ in $\mathbf{1}$ leads to doping-induced charge stripping phenomenon. ${ }^{25}$

DFT calculations ${ }^{26}$ on a simplified model for $\mathbf{1}$, [PdAg $\left.{ }_{20}\left\{\mathrm{~S}_{2} \mathrm{PH}_{2}\right\}_{12}\right]\left(\mathbf{1}^{\prime}\right)$ shows an electronic structure related to that of previously reported isoelectronic $M @ A_{20}(M=A u, A g)$ species. ${ }^{20,22}$ In other words, 1 can be formally described as an 8-electron $\left[\mathrm{PdAg}_{12}\right]^{4+}$ superatomic core passivated by eight $\mathrm{Ag}^{+}$ and twelve dtp-ions. The occupation of the icosahedron center by Pd is computed to be preferred over any of the other metallic positions by more than $20 \mathrm{kcal} / \mathrm{mol}$. This result was already found for an Au-doped isoelectronic relative of $1 .^{20 a}$ This is related to the heteroatom electronegativity which is larger than that of $\mathrm{Ag}$. The preference for Pd occupying the icosahedron center (by more than $20 \mathrm{kcal} / \mathrm{mol}$ ) is related to its larger electronegativity than that of $\mathrm{Ag}$. Indeed, replacing $\mathrm{Pd}$

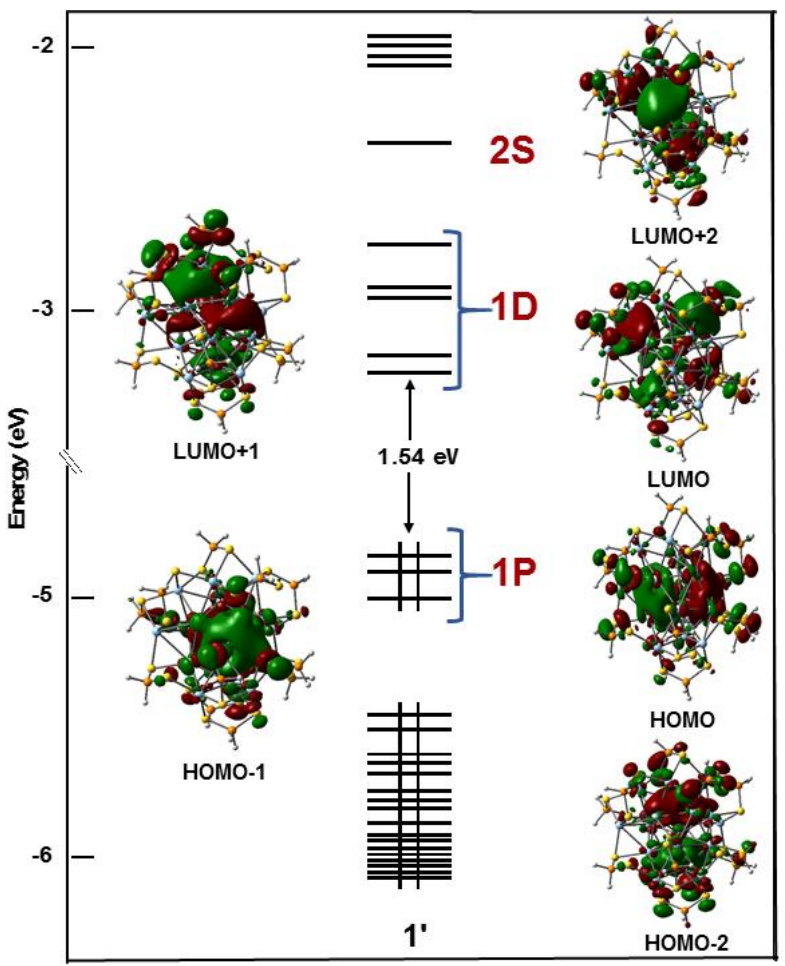

Fig. 2 Kohn-Sham molecular orbital diagram of 1'. 

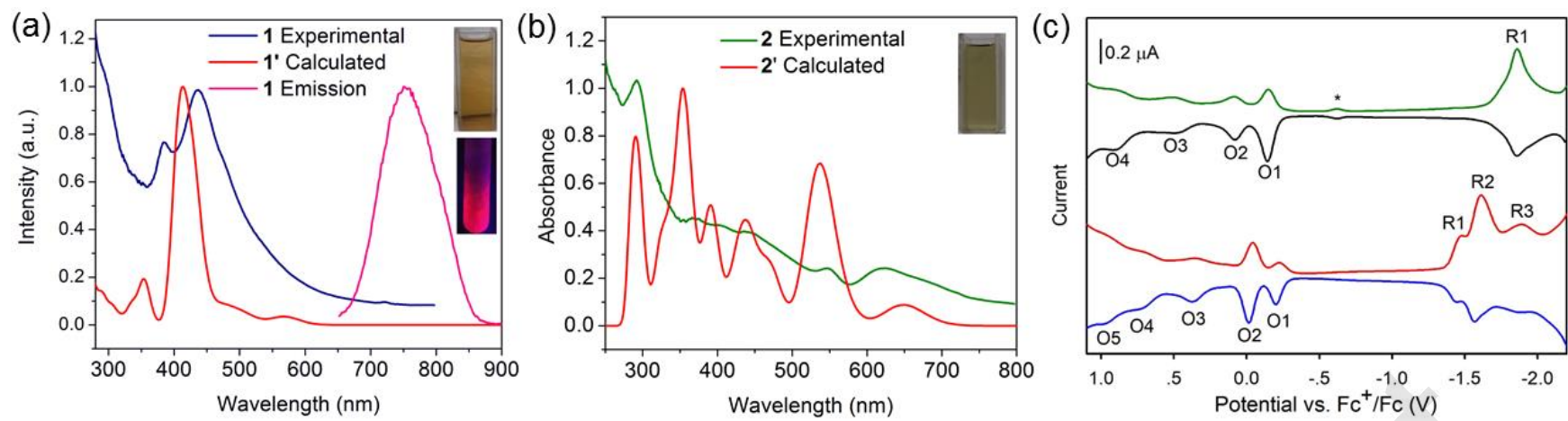

Fig. 3 (a) UV-vis spectrum (left) of 1 in $1 \times 10^{-5} \mathrm{M} \mathrm{CH}_{2} \mathrm{Cl}_{2}$ and normalized emission spectrum (right) of 1 in MeTHF at $77 \mathrm{~K}$. The TDDFT-simulated spectrum of $\mathbf{1}^{\prime}$ is superimposed in red. The insets show the photograph of solution of $\mathbf{1}$ in $\mathrm{CH}_{2} \mathrm{Cl}_{2}$ at room temperature (top) and 2-Methyl THF under UV irradiation at $77 \mathrm{~K}$ (bottom). (b) UV-vis spectrum of 2 in $1 \times 10^{-5} \mathrm{M} \mathrm{CH}_{2} \mathrm{Cl}_{2}$ and the TD-DFT-simulated spectrum of 2'. The inset shows the photograph of solution of $\mathbf{2}$ in $\mathrm{CH}_{2} \mathrm{Cl}_{2}$ at room temperature. (c) SWVs of $\mathbf{1}$ (top) and 2 (bottom) recorded in $\mathrm{CH}_{2} \mathrm{Cl}_{2}$ at 233K. Internal reference decamethylferrocene is denoted by an asterisk.

by $\mathrm{Ag}^{+}$in $\mathbf{1}^{\prime}$, leads to (averaged) natural atomic orbital (NAO) charges of $-0.44,+0.20$, and +0.58 for $\mathrm{Ag}_{\text {center, }} \mathrm{Ag}_{\text {ico }}$ and $\mathrm{Ag}_{\text {cap }}$, respectively, indicating that the electron-rich central position is strongly favored for $\mathrm{Pd}$ occupation. The computed NAO charges for 1 ' are $-0.99,+0.20$, and +0.57 for $\mathrm{Pd}, \mathrm{Ag}_{\text {ico }}$ and $\mathrm{Ag}_{\text {cap }}$, respectively. They are in line with the XPS results. The MO diagram of $\mathbf{1}^{\prime}$ is shown in Fig. 2 . The three highest occupied and five lowest unoccupied orbitals can be viewed as the superatomic $1 \mathrm{P}$ and $1 \mathrm{D}$ levels, respectively (with some external shell admixture) whereas the LUMO+6 can be identified as the $2 \mathrm{~S}$ level.

The UV-vis spectrum of $\mathbf{1}$ shows two major broad absorption bands at 384 and $436 \mathrm{~nm}$ (Fig. 3a). The absorption spectrum of 1 recorded in $\mathrm{CH}_{2} \mathrm{Cl}_{2}$ at $25{ }^{\circ} \mathrm{C}$ remains unchanged for a month (Fig. S8 ESIt) indicating high stability. The simulated TD-DFT26 spectrum of 1' (Fig. 3a) exhibits also two major band at 353 and $413 \mathrm{~nm}$ which can be attributed to metal-to-metal charge transfer (MMCT) $1 \mathrm{P} \rightarrow 2 \mathrm{~S}$ and $1 \mathrm{P} \rightarrow 1 \mathrm{D}$ transitions. 1 displays photoluminescence in solution at cryogenic temperature. Its emission maximum in 2-methyl tetrahydrofuran (MeTHF) at $77 \mathrm{~K}$ occurs at $748 \mathrm{~nm}$ (Fig. 3a and Fig. S9, ESI+). The intensity decreases sharply upon raising the temperature to $298 \mathrm{~K}$ (Fig. S10, ESI+).

Cyclic voltammetry (CV) and square wave voltammetry (SWV) of 1 were performed in $\mathrm{CH}_{2} \mathrm{Cl}_{2}$ at various temperatures (Fig. 3c, and Fig. S11-S12, ESIt). The cyclic voltammogram at $233 \mathrm{~K}$ displays an irreversible reduction at $E_{\mathrm{pc}}=-1.97 \mathrm{~V}$ (vs. $\mathrm{Fc}^{+} / \mathrm{Fc}$ ) and four quasi reversible oxidation processes at $E_{1 / 2}=$ $0.12,0.09,0.52$ and $0.91 \vee(F i g . ~ S 11, E S I+)$. Accordingly, the square wave voltammogram at $233 \mathrm{~K}$ showed four oxidation peaks at $-0.15(\mathrm{O} 1), 0.09(\mathrm{O} 2), 0.51(\mathrm{O} 3)$, and $0.90(\mathrm{O} 4)$ and one reduction peak at $-1.86 \mathrm{~V}$ (Fig. 3c). The first oxidation and reduction peaks correspond to $[1]^{+1 / 0}(\mathrm{O} 1)$ and $[\mathbf{1}]^{0 /-1}(\mathrm{R} 1)$. The electrochemical HOMO-LUMO gap, which is the difference between $\mathrm{O} 1$ and R1, is calculated to be $1.71 \mathrm{eV}$ for $\mathbf{1}$. To our knowledge, this is the first CVs/SWVs report of palladium doped silver NC. The calculated value for this electrochemical $\operatorname{gap}^{26}(1.46 \mathrm{eV})$, for $\mathbf{1}^{\prime}$ agrees well with experiment.
In an attempt to synthesize multi-palladium-doped silver clusters we have isolated $\left[\mathrm{Pd}_{6} \mathrm{Ag}_{14}(\mathrm{~S})\left\{\mathrm{S}_{2} \mathrm{P}\left(\mathrm{O}^{n} \mathrm{Pr}\right)_{2}\right\}_{12}\right](2)$ in $22 \%$ yield, along with 1 by increasing the $\left[\mathrm{Pd}\left\{\mathrm{S}_{2} \mathrm{P}\left(\mathrm{O}^{n} \mathrm{Pr}\right)_{2}\right\}_{2}\right]$ amount (Scheme S2, ESIt). 2 was purified by thin layer chromatography. It crystallizes in the triclinic $P(-) 1$ space group. Its $\mathrm{X}$-ray structure exhibits a sulfide-centered $\mathrm{Pd}_{6} \mathrm{Ag}_{14}$ metallic framework protected by $12 \mathrm{dtp}$ ligands with an idealized $\mathrm{S}_{6}$ symmetry (Fig. $4 \mathrm{a}-\mathrm{C}$, and Fig. S13, ESI ${ }^{+}$). It can be visualized as a distorted $\mathrm{Pd}_{6} \mathrm{Ag}_{2}\left(\mathrm{Ag}=\mathrm{Ag}_{\mathrm{A}}\right)$ rhombohedron; the faces of which are capped by six $\mathrm{Ag}_{\mathrm{B}}$ atoms (Fig. $4 \mathrm{~d}$ and $4 \mathrm{e}$ ). Furthermore, this hexacapped rhombohedron has its six $\mathrm{Ag}_{\mathrm{B}} \mathrm{PdPdAg}_{\mathrm{B}}$ butterflies capped by six additional $\mathrm{Ag}_{\mathrm{C}}$ atoms (Fig. $4 \mathrm{e}$ and $4 \mathrm{f}$ ). Thus, the structure of $\mathbf{2}$ is completely different from that of $\mathbf{1}$ and related 8-electron species. ${ }^{20,22,23}$

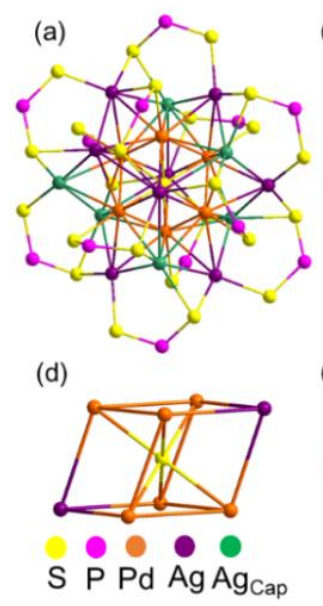

(b)

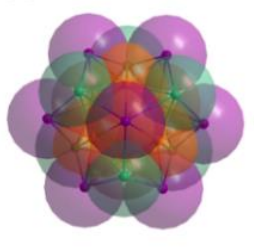

(e)

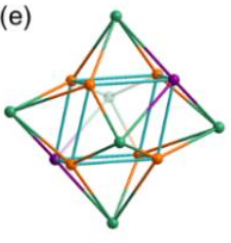

(c)

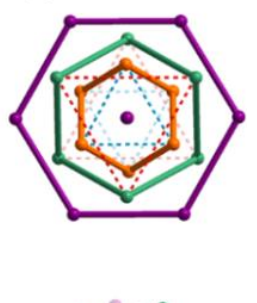

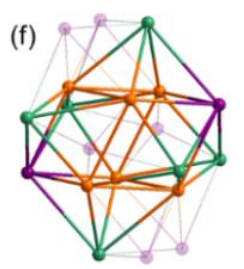

Fig. 4 (a) Total structure of $\left[\mathrm{Pd}_{6} \mathrm{Ag}_{14} \mathrm{~S}\left\{\mathrm{~S}_{2} \mathrm{P}\left(\mathrm{O}^{n} \mathrm{Pr}\right)_{2}\right\}_{12}\right]$ (2) with propoxy groups omitted for clarity. (b) The $\mathrm{Pd}_{6} \mathrm{Ag}_{14}$ core. (c) View of the $\mathrm{Pd}_{6} \mathrm{Ag}_{14}$ core along the $C_{3}$ axis. (d) The sulfiderhombohedron. (f) The whole $\mathrm{Pd}_{6} \mathrm{Ag}_{14}$ metal framework.

The encapsulated sulfur atom is connected to the six Pd centers in a distorted octahedral coordination mode (average Pd-S distance: 2.271(7) Å). Surprisingly, there has been no 
example where sulfur is coordinated to six Pd atoms. The Pd-Pd distances (2.9088(5)-2.9293(5) $\AA$ ) are longer those in bulk Pd (ca. Pd-Pd = $2.76 \AA ̊$ ). ${ }^{27} \mathrm{The} A \mathrm{Ag}_{\mathrm{A}, \mathrm{B}} \mathrm{Pd}(2.7672(5)-3.1903(5) \AA ̊$ ) and $\mathrm{Ag}_{\mathrm{A}, \mathrm{B}}-\mathrm{Ag}_{\mathrm{A}, \mathrm{B}}(3.3017(5)-3.2464(5) \AA)$ distances are longer than those involving the $\mathrm{Ag}_{\mathrm{C}}$ atoms ( $\mathrm{Ag}_{\mathrm{C}}-\mathrm{Pd}$ : 2.8452(6) 2.8733(6) $\AA$ ) and $\mathrm{Ag}_{\mathrm{c}}-\mathrm{Ag}_{\mathrm{c}}(2.8808(6)-2.9627(6) \AA)$. To the best of our knowledge $\mathbf{2}$ is the first example among the noble metal clusters where a hexapalladium core is entrapped inside an $\mathrm{Ag}$ cluster.

The entire $\mathrm{Pd}_{6} \mathrm{Ag}_{14}$ metallic core in $\mathbf{2}$ is wrapped by twelve dtp ligands which are equally distributed in two layers of six ligands (inner and outer) around the $S_{6}$ axis and coordinated in a trimetallic triconnectivity $\left(\eta^{3}: \mu_{2}, \mu_{1}\right)$ and tetrametallic tetraconnectivity $\left(\eta^{4}: \mu_{2}, \mu_{2}\right)$ fashion (Fig. S14, ESI + ). The average Pd-S (2.370 $⿱$ ) and Ag-S (2.648 $\AA$ ) bond distances are in the range of that one would expect from the literature. ${ }^{28}$ Discarding the various metal-metal contacts, Pd is linearly coordinated to two $\mathrm{S}$ atoms (including the sulfide), $\mathrm{Ag}_{\mathrm{A}}$ is tricoordinated, whereas $\mathrm{Ag}_{\mathrm{B}}$ and $\mathrm{Ag}_{\mathrm{C}}$ are bicoordinated.

The ${ }^{1} \mathrm{H}$ NMR spectrum of $\mathbf{2}$ is consistent with the presence of the ${ }^{n} \mathrm{Pr}$ groups (Fig. S15, ESIT). The ${ }^{31 P}$ NMR spectrum of 2 shows two different signals, corresponding to the two types of coordination modes (Fig. S16, ESIt). Moreover, the ${ }^{31}$ P VT NMR spectra of $\mathbf{2}$ show conservation of the two signals, indicating that the molecular structure is retained in solution (Fig. S17, ESI $)$ ). The positive-ion ESI mass spectrum of 2 also confirms its composition, with a prominent band for $[2+A g]^{+}$at $m / z 4848.2$ (calcd. 4847.9) and its simulated isotopic pattern matches well with the experimental observation (Fig. S18, ESI + ). The XPS spectrum of $\mathbf{2}$ in the $\mathrm{Pd} 3 \mathrm{~d}$ region reveals binding energies at 335.6 and $340.7 \mathrm{eV}$, corresponding to $\operatorname{Pd}(0) 3 d_{5 / 2}$ and $3 d_{3 / 2}$, respectively (Fig. S19, ESI+).

DFT calculations on a simplified model for $\mathbf{2}^{26}$ $\left.\left[\mathrm{Pd}_{6} \mathrm{Ag}_{14}(\mathrm{~S})\left\{\mathrm{S}_{2} \mathrm{PH}\right)_{2}\right\}_{12}\right]\left(\mathbf{2}^{\prime}\right)$ supports the view of a cluster made up of $d^{10}$ metal centers $(P d(0)$ and $A g(I))$. The NAO charges of $\mathrm{Pd}, \mathrm{Ag}_{\mathrm{A}}, \mathrm{Ag}_{\mathrm{B}}$ and $\mathrm{Ag}_{\mathrm{C}}$ are $-0.30,+0.58,+0.49$ and +0.57, respectively, that of the hypercoordinated central sulfide is 0.36, indicating important charge transfer to the Pd centers, thus substantial covalency. Consistently, the corresponding Pd$S$ Wiberg bond index (WBI) of 0.278 compares well with that of the Pd-S(dtp) bonds (0.335). The electron deficiency of the 16and 14-electron centers $\left(\mathrm{Ag}_{\mathrm{A}}\right.$ and $\mathrm{Pd}, \mathrm{Ag}_{B}$ and $\mathrm{Ag}_{\mathrm{C}}$, respectively) is partly compensated by weak metal-metal bonding associated with some $4 d \rightarrow 4 s / 4 p$ electron transfer. Indeed, the corresponding WBls remain within the range of what is expected to occur for metallophilic $\mathrm{d}^{10}-\mathrm{d}^{10}$ interactions ${ }^{29}$ ( $\mathrm{Pd}$ $\mathrm{Pd}$ : 0.077; $\mathrm{Ag}-\mathrm{Ag}$ range: 0.055-0.074; $\mathrm{Ag}-\mathrm{Pd}$ range: 0.0570.092). ${ }^{30}$ This electron deficiency can be traced in the nature of the lowest unoccupied MOs (Fig. S20, ESIt), whereas the highest occupied MOs are $3 \mathrm{~d}(\mathrm{Pd})$ combinations.

The absorption spectrum of $\mathbf{2}$ shows multiple bands in the range 290 to $620 \mathrm{~nm}$ and an intense band at $291 \mathrm{~nm}$ (Fig. 3b). The absorption spectrum recorded in $\mathrm{CH}_{2} \mathrm{Cl}_{2}$ at $25{ }^{\circ} \mathrm{C}$ remains unchanged for a month (Fig. S21, ESI + ) indicating high stability. The simulated TD-DFT ${ }^{26}$ spectrum of 2' (Fig. 3b) agrees well with experiment. The low energy band is of palldium-to-silver charge transfer (PdAgCT) nature and the next one of $\mathrm{Ag}(\mathrm{d}) \mathrm{Ag}(\mathrm{sp}) \mathrm{CT}$ nature.

CVs and SWVs were also performed on 2 in $\mathrm{CH}_{2} \mathrm{Cl}_{2}$ at various temperatures (Fig. 3c, Fig. S22 and S23, ESIt). The cyclic voltammogram at $233 \mathrm{~K}$ displays three irreversible reductions at $\mathrm{Epc}=-1.47,-1.67$ and $-1.91 \mathrm{~V}$. Four irreversible oxidations at Epa $=-0.13,0.45,0.76,1.01 \mathrm{~V}$, and one quasireversible oxidation process at $\mathrm{E}_{1 / 2}=-0.01 \mathrm{~V}$ were observed while the fifth oxidation process was clearly observed in the SWV. The corresponding values of the SWV were obtained at 1.48 (R1), -1.62 (R2), -1.89 (R3) for the cathodic events, and $0.20(01),-0.01(02), 0.38(03), 0.72(04), 0.97$ (O5) for the anodic ones (Fig. 3c). Compared with 1, 2 exhibits more reductions and oxidations in which they are much easier to be accessed. The resulting electrochemical HOMO-LUMO gap is decreased to $1.28 \mathrm{eV}$. Its DFT-computed counterpart calculated $^{26}$ for $\mathbf{2}^{\prime}$ is also $1.28 \mathrm{eV}$.

During the course of synthesis of $\mathbf{2}$, we also observe the formation of 1, thus were interested to see the connection between $\mathbf{1}$ and $\mathbf{2}$. As given in Scheme S2, we propose that the formation of $\mathbf{2}$ is associated with the redox reaction between the residual amount of $\mathrm{Ag}(0)$ formed in parallel to the formation of 1 with $\mathrm{Pd}(\mathrm{II})$ and $\mathrm{S}$ atom. Since, $2 \mathrm{Ag}(0)$ can reduce one $\mathrm{Pd}(\mathrm{II})$ into $\mathrm{Pd}(0)$ and one $\mathrm{S}$ atom into $\mathrm{S}^{2-}$ independently, then 2 accommodates $14 \mathrm{Ag}^{+}, 6 \mathrm{Pd}^{0}$ and $1 \mathrm{~S}^{2-}$ ions (Fig. S24, ESI + ). Note that the sulfide is generated from a $\mathrm{P}-\mathrm{S}$ bond cleavage of dtp ligand by the $\mathrm{LiBH}_{4} \cdot \mathrm{THF}$ reducing agent.

\section{Conclusions}

In conclusion, one pot synthesis and full characterization of the molecularly pure, charge neutral Pd doped silver NC $\left[\mathrm{PdAg}_{20}\left\{\mathrm{~S}_{2} \mathrm{P}\left(\mathrm{O}^{n} \mathrm{Pr}\right)_{2}\right\}_{12}\right]$ is presented. It displays a $\mathrm{Pd}$-centered $\mathrm{Ag}_{12}$ icosahedron capped by 8 silver atoms in $C_{2}$ symmetry. Apart from its high stability, 1 features red emission at cryogenic temperature and doping induced charge stripping. Additionally, we have isolated the $\mathrm{Pd}_{6} \mathrm{Ag}_{14}$ bimetallic NC (2) in which an octahedral hexa-palladium( 0 ) core is embodied within a silver(I) cluster, the first one in literature. Bonding characteristics of both alloys have been fully rationalized by DFT calculations and among them hexa-palladium doped silver NC displays a smaller electrochemical HOMO-LUMO gap. We anticipate that the isolation of these novel bimetallic NCs in their pure forms makes a new frontier in the alloy synthesis with enhanced synergistic properties for multiple potential applications such as $\mathrm{C}-\mathrm{C}$ bond cross-coupling reactions.

\section{Conflicts of interest}

There are no conflicts to declare.

\section{Acknowledgements}

This work was supported by the Ministry of Science and Technology in Taiwan (MOST 106-2113-M-259-010). The ANR-MOST 2018 
program (project Nanoalloys) and the GENCl computer resource center (grant A0030807367).

\section{Notes and references}

1 (a) M. S. Bootharaju, C. P. Joshi, M. R. Parida, O. F. Mohammed and O. M. Bakr, Angew. Chem., Int. Ed., 2016, 55, 922-926; (b) R. P. B. Silalahi, K. K. Chakrahari, J.-H. Liao, S Kahlal, Y.-C. Liu, M.-H. Chiang, J.-Y. Saillard and C. W. Liu, Chem. Asian J., 2018, 13, 500-504; (c) Z. Lei, X.-Y. Pei, Z.-G. Jiang and Q.-M. Wang, Angew. Chem. Int. Ed., 2014, 53 12771-12775; (d) S. Wang, X. Meng, A. Das, T. Li, Y. Song, T. Cao, X. Zhu, M. Zhu and R. Jin, Angew. Chem. Int. Ed., 2014, 53, 2376-2380; (e) T. Udayabhaskararao, Y. Sun, N. Goswami, S. K. Pal, K. Balasubramanian and T. Pradeep, Angew. Chem. Int. Ed., 2012, 51, 2155-2159.

2 (a) H. Qian, D.-e. Jiang, G. Li, C. Gayathri, A. Das, R. R. Gil and R. Jin, J. Am. Chem. Soc., 2012, 134, 16159-16162; (b) Y. Liu, X. Chai, X. Cai, M. Chen, R. Jin, W. Ding and Y. Zhu, Angew. Chem. Int. Ed., 2018, 57, 9775-9779; (c) C. Yao, J. Chen, M.-B. Li, L. Liu, J. Yang and Z. Wu, Nano Lett., 2015, 15, 1281-1287, (d) S. Wang, S. Jin, S. Yang, S. Chen, Y. Song. J. Zhang and M. Zhu, Sci. Adv., 2015, 1:e1500441; (e) S. Xie, H. Tsunoyama, W. Kurashige, Y. Negishi and T. Tsukuda, ACS Catal., 2012, 2, 1519-1523.

3 (a) C. A. Fields-Zinna, M. C. Crowe, A. Dass, J. E. F. Weaver and R. W. Murray, Langmuir, 2009, 25, 7704-7710; (b) K Kwak, Q. Tang, M. Kim, D.-e. Jiang and D. Lee, J. Am. Chem. Soc. 2015, 137, 10833-10840; (c) L. Liao, S. Zhou, Y. Dai, L. Liu, C. Yao, C. Fu, J. Yang and Z. Wu, J. Am. Chem. Soc. 2015, 137, 9511-9514; (d) J.-P. Choi, C. A. Fields-Zinna, R. L. Stiles, R. Balasubramanian, A. D. Douglas, M. C. Crowe and R. W. Murray, J. Phys. Chem. C, 2010, 114, 15890-15896.

4 (a) Z. Wang, H.-F. Su, M. Kurmoo, C.-H. Tung, D. Sun and L.S. Zheng, Nat. Commun., 2018, 9, 2094-2101; (b) J.-Y. Liu, F. Alkan, Z. Wang, Z.-Y. Zhang, M. Kurmoo, Z. Yan, Q.-Q. Zhao, C. M. Aikens, C.-H. Tung and D. Sun, Angew. Chem. Int. Ed. 2019, 58, 195-199; (c) S.-F. Yuan, C.-Q. Xu, J. Li and Q.-M. Wang, Angew. Chem. Int. Ed., 2019, 58, 5906-5909; (d) J.-W. Liu, Z. Wang, Y.-M. Chai, M. Kurmoo, Q.-Q. Zhao, X.-P. Wang, C.-H. Tung and D. Sun, Angew. Chem. Int. Ed. 2019, 58, 6276 6279; (e) S.-S. Zhang, F. Alkan, H.-F. Su, C. M. Aikens, C.-H. Tung and D. Sun, J. Am. Chem. Soc., 2019, 141, 4460-4467.

5 (a) Y. Negishi, W. Kurashige, Y. Niihori, T. I wasa and K Nobusada, Phys. Chem. Chem. Phys. 2010, 12, 6219-6225; (b) Y. Negishi, K. Igarashi, K. Munakata, W. Ohgake, K. Nobusada, Chem. Commun., 2012, 48, 660-662.

6 S. L. Christensen, M. A. MacDonald, A. Chatt, P. Zhang, H. Qian and R. Jin, J. Phys. Chem. C, 2012, 116, 26932-26937.

7 S. Wang, Y. Song, S. Jin, X. Liu, J. Zhang, Y. Pei, X. Meng, M. Chen, P. Li and M. Zhu, J. Am. Chem. Soc. 2015, 137, 40184021.

8 L. Liao, S. Zhou, Y. Dai, L. Liu, C. Yao, C. Fu, J. Yang and Z. Wu, J. Am. Chem. Soc., 2015, 137, 9511-9514.

9 Y. Negishi, K. Munakata, W. Ohgake and K. Nobusada, J. Phys. Chem. Lett., 2012, 3, 2209-2214.

10 (a) Y. Negishi, T. Iwai and M. Ide, Chem. Commun., 2010, 46, 4713-4715; (b) C. Kumara, C. M. Aikens and A. J. Dass, Phys.
Chem. Lett., 2014, 5, 461-466; (c) D. R. Kauffman, D. Alfonso, C. Matranga, H. Qian and R. Jin, J. Phys. Chem. C, 2013, 117, 7914-7923.

11 J. Yan, H. Su, H. Yang, S. Malola, S. Lin, H. Hakkinen and N. Zheng, J. Am. Chem. Soc. 2015, 137, 11880-11883.

12 M. S. Bootharaju, S. M. Kozlov, Z. Cao, M. Harb, N. Maity, A. Shkurenko, M. R. Parida, M. N. Hedhili, M. Eddaoudi, O. F. Mohammed, O. M. Bakr, L. Cavallo and J.-M. Basset, J. Am. Chem. Soc., 2017, 139, 1053-1056.

13 (a) M. S. Bootharaju, S. M. Kozlov, Z. Cao, A. Shkurenko, A M. El-Zohry, O. F. Mohammed, M. Eddaoudi, O. M. Bakr, L. Cavallo and J.-M. Basset, Chem. Mater., 2018, 30, 2719-2725; (b) X. Lin, C. Liu, K. Sun, R. Wu, X. Fu and J. Huang, Nano Res. 2019, 12, 309-314.

14 H. Shen and T. Mizuta, Chem. Asian J., 2017, 12, 2904-2907.

15 L. Z. He, J. Y. Yuan, N. Xia, L. W. Liao, X. Liu, Z. B. Gan, C. M. Wang, J. L. Yang and Z. K. Wu, J. Am. Chem. Soc., 2018, 140, 3487-3490.

16 N. Yan, L. Liao, J. Yuan, Y.-j. Lin, L.-h. Weng, J. Yang and Z. Wu, Chem. Mater., 2016, 28, 8240-8247.

17 X. Liu, J. Yuan, C. Yao, J. Chen, L. Li, X. Bao, J. Yang and Z. Wu. J. Phys. Chem. C, 2017, 121, 13848-13853.

18 F. Tian and R. Chen, J. Am. Chem. Soc., 2019, 10.1021/jacs.9b02162.

19 Y.-R. Lin, P. V. V. N. Kishore, J.-H. Liao, S. Kahlal, Y.-C. Liu, M.H. Chiang, J.-Y. Saillard and C. W. Liu, Nanoscale, 2018, 10, 6855-6860.

20 (a) W.-T. Chang, P.-Y. Lee, J.-H. Liao, K. K. Chakrahari, S. Kahlal, Y.-C. Liu, M.-H. Chiang, J.-Y. Saillard and C. W. Liu, Angew. Chem. Int. Ed., 2017, 56, 10178-10182; (b) J.-H. Liao, S. Kahlal, Y.-C. Liu, M.-H. Chiang, J.-Y. Saillard and C. W. Liu, J. Clust. Sci. 2018, 29, 827-835.

21 K. K. Chakrahari, R. P. B. Silalahi, T.-H. Chiu, X. Wang, N. Azrou, S. Kahlal, Y. -C. Liu, M.-H. Chiang, J.-Y. Saillard and C. W. Liu, Angew. Chem. Int. Ed., 2019, 58, 4943-4947.

22 R. S. Dhayal, J.-H. Liao, Y.-C. Liu, M.-H. Chiang, S. Kahlal, J.-Y. Saillard and C. W. Liu, Angew. Chem. Int. Ed., 2015, 54, 37023706.

23 S. Sharma, K. K. Chakrahari, J.-Y. Saillard and C. W. Liu, Acc. Chem. Res., 2018, 51, 2475-2483.

24 R. S. Dhayal, Y.-R. Lin, J.-H. Liao, Y.-J. Chen, Y.-C. Liu, M.-H. Chiang, S. Kahlal, J.-Y. Saillard and C. W. Liu, Chem. Eur. J., 2016, 22, 9943-9947.

25 A. Ghosh, O. F. Mohammed and O. M. Bakr, Acc. Chem. Res. 2018, 51, 3094-3103.

26 Computational details in the SI.

27 (a) T. Murahashi, H. Kurosawa, Coord. Chem. Rev. 2002, 231, 207-228; (b) M. Teramoto, K. Iwata, H. Yamaura, K. Kurashima, K. Miyazawa, Y. Kurashige, K. Yamamoto and T. Murahashi, J. Am. Chem. Soc., 2018, 140, 12682-12686.

28 Y.-J. Kim, K.-Y. Choi, S. G. Lee, Z. N. Zheng and S. W. Lee, Bull. Korean Chem. Soc., 2014, 35, 1205-1208.

29 C. W. Liu, P.-K. Liao, C.-S. Fang, J.-Y. Saillard, S. Kahlal and J.C. Wang, Chem. Commun., 2011, 47, 5831-5833.

30 Introducing dispersion corrections slightly strengthens $d^{10}$ $\mathrm{d}^{10}$ bonding (Table S2). 